\section{Mental Tracking}

G. Combs ${ }^{1}$ and E. Power ${ }^{1,2}$

${ }^{1}$ Legal Psychology (Psychology and Law), Neuropsychology, Clinical Psychology, Chicago School of Professional Psychology, Chicago, IL, USA

${ }^{2}$ College of Saint Rose, Albany, NY, USA

\section{Definition}

Mental tracking is the ability to follow a sequence of events from one point to another. To do this, one must be able to hold material in his or her mind while manipulating the information mentally in order to switch from one cognitive set to another (The American psychiatric publishing textbook of neuropsychiatry 2008). To do so requires the capacity to maintain attention and short-term/working memory. This is important in a wide variety of tasks, and an inability to mentally track might have effects on oral verbalizations, reading comprehension, arithmetic, as well as following through with simple everyday tasks to completion. An example of this might be something as simple as starting one's car or as complex as driving all the way to work. There are many disorders that may have an effect on how one mentally tracks: Alzheimer's, epilepsy, and Lyme disease are a few among many. There are many tools available intending to measure mental tracking. The most famous test is the Trail-Making Test (2008), which originated around 1944. Individuals with general attentional deficits may also have difficulty tracking information. Additionally, one's capacity to track multiple bits of information at once is the only documentable mental change following a traumatic brain injury (TBI) or brain disease.

\section{References and Readings}

Hales, R. (2008). The American psychiatric publishing textbook of psychiatry. Arlington: American Psychiatric Publishing.

Lezak, M. D., Howieson, D. B., Bigler, E. D., \& Tranel, D. (2012). Neuropsychological assessment. New York: Oxford University Press. 